\title{
Induction of Analgesia Using Atorvastatin in Experimental Diabetic Neuropathy through NMDA Receptor and Inflammatory Cytokine Inhibition
}

Karim Hemati1 ${ }^{1}$, Mohammad Yahya Karimi², Azam Hosseinzadeh², Meysam Abolmaali ${ }^{3,4}$, Nabaa Najjar ${ }^{5,6}$, Mohamad-Reza Aghanoori ${ }^{7}$ and Vahid Nikoui2,*

${ }^{1}$ Department of Anesthesiology, Iran University of Medical Sciences, Tehran, Iran
2 Razi Drug Research Center, Iran University of Medical Sciences, Tehran, Iran
${ }^{3}$ Shefa Neuroscience Research Center, Khatam Alanbia Hospital, Tehran, Iran
${ }^{4}$ Student Research Committee, School of Medicine, Iran University of Medical Sciences, Tehran, Iran
${ }^{5}$ Department of Biochemistry, School of Medicine, Iran University of Medical Sciences, Tehran, Iran
${ }^{6}$ Cellular and Molecular Research Center, Iran University of Medical Sciences, Tehran, Iran
7 Division of Neurodegenerative Disorders, St. Boniface Hospital Albrechtsen Research Center, University of Manitoba, Winnipeg, MB, Canada

* Corresponding author: Vahid Nikoui, Razi Drug Research Center, Iran University of Medical Sciences, Hemmat Expressway, Tehran, Iran. Tel: +982186703145; Fax: +982188622523; Email: nikoui.v@iums.ac.ir

Received 2020 0ctober 06; Revised 2020 November 18; Accepted 2020 December 12.

\begin{abstract}
Background: Diabetic neuropathy is a complication of diabetes causing damage to the nerves.

Objectives: Considering the neuroprotective anti-inflammatory antioxidant characteristics of statins, the current study aimed at determining the effects of atorvastatin on diabetic neuropathy through assessing the involvement of the $N$-methyl-D-aspartic acid (NMDA) receptor, factors of oxidative stress, and inflammatory cytokines in rats with diabetes.

Methods: Male rats were randomly assigned into six groups of saline- and atorvastatin-treated controls, streptozotocin-induced diabetic animals treated with vehicle, diabetic animals treated with morphine $(5 \mathrm{mg} / \mathrm{kg})$, and rats treated with atorvastatin $(10 \mathrm{mg} / \mathrm{kg} / \mathrm{day} \mathrm{for} 10$ weeks) alone or in combination with NMDA receptor agonist. The hot plate and formalin tests were carried out on the rats. Moreover, malondialdehyde level, catalase and superoxide dismutase activities, and levels of interleukin 1 beta (IL-1ß), interleukin 6 (IL-6), and tumor necrosis factor alpha (TNF- $\alpha$ ) in the dorsal root ganglia (DRG) of the animals were measured. Finally, the expression of the NMDA receptor in DRG was investigated in the current study.

Results: According to the findings, diabetes resulted in analgesia in all the tests, and pretreatment with atorvastatin exacerbated diabetes-induced analgesic effects in the hot plate test and early phase of the formalin test $(\mathrm{P} \leq 0.01$ and $\mathrm{P} \leq 0.05$ in comparison to those reported for the diabetic vehicle-treated group, respectively). The injection of NMDA could reverse the atorvastatin-induced analgesia in the hot plate test $(\mathrm{P} \leq 0.05)$. Diabetes caused an increase in the levels of IL-1 $\beta$, IL-6, and TNF- $\alpha$ in DRG in comparison to those reported for the control group $(\mathrm{P} \leq 0.05)$. Furthermore, the pretreatment of rats using atorvastatin could significantly reverse the increase in TNF- $\alpha$ level $(\mathrm{P} \leq 0.05)$.

Conclusion: Atorvastatin showed analgesic properties, which might be acting through NMDA receptors and reduction of inflammatory cytokines.
\end{abstract}

Keywords: Atorvastatin, Diabetic neuropathy, Inflammatory cytokines, NMDA receptor, Oxidative stress factors

\section{Background}

Diabetes mellitus is considered a group of metabolic diseases characterized by an uncontrolled elevation of blood sugar and impaired insulin signaling (1). The complications of diabetes mellitus include retinopathy, nephropathy, neuropathy, ischemic heart disease, peripheral vascular disease, and cerebrovascular disease (macrovascular) approximately occurring in one-third to one-half of individuals with diabetes and resulting in organ and tissue damage (2). These complications affect the quality of life and impose a great burden on the national health care system $(3,4)$.

Diabetic neuropathy is the most common form of neuropathy, resulting in hospitalization more frequently than other diabetic complications (5). Diabetic neuropathy is described as the signs and symptoms of peripheral nerve dysfunction, including pain, paresthesia, and loss of sensation, in diabetic patients. In addition, it is responsible for $50-75 \%$ of nontraumatic amputations $(6,7)$. Despite the attempts to diagnose the etiology of diabetic neuropathy, the exact pathophysiological mechanisms of this complication remain to be elucidated (8). Oxidative stress and induction of inflammatory pathways in response to the long-term elevated blood glucose level have been postulated as mechanisms involved in the development of diabetic neuropathy (9).

The persistent overstimulation of the $\mathrm{N}$-methyl-Daspartic acid (NMDA) receptor is reported to contribute to both inflammation and nerve injuryinduced central sensitization within the dorsal horn. The NMDA receptor is a specific type of ionotropic glutamate receptor identified in neurons. The main mechanisms of NMDA receptors are described as

Copyright (c) 2021, Author(s). This is an open-access article distributed under the terms of the Creative Commons Attribution-NonCommercial 4.0 International License (http://creativecommons.org/licenses/by-nc/4.0/) which permits copy and redistribute the material just in noncommercial usages, provided the original work is properly cited 
controlling synaptic plasticity and memory function (10). Therefore, NMDA receptor antagonists may possibly impede or reverse nerve injury and diabetic neuropathy, leading to the reduction of hyperalgesia and allodynia $(11,12)$.

In the past few years, various studies have been carried out for the evaluation of the effect of presynaptic NMDA receptor antagonists on neuropathic pain $(13,14)$. However, the clinically available NMDA receptor antagonists cause substantial side effects at potentially therapeutic doses, including psychomimetic effects, nausea, vomiting, and impairment of cognitive and motor function, limiting their clinical uses (15). Therefore, the use of clinically safe agents with the ability to antagonize the NMDA receptor is much required to protect diabetic patients from NMDA-induced neuronal damage.

Atorvastatin as a member of the statin group of drugs (i.e., 3-hydroxy-3-methylglutaryl-coenzyme A [HMG-CoA] reductase inhibitors) is administered for the reduction of serum cholesterol levels in cardiovascular diseases. In addition to the lipidlowering activity, atorvastatin is reported with other pharmacological characteristics, including antioxidant and anti-inflammatory activities, suggesting the pleiotropic impacts of atorvastatin (16). Atorvastatin reduces the generation of reactive oxygen species (ROS) through the suppression of nicotinamide adenine dinucleotide phosphate (NADPH) oxidase activity and enhancement of the activity and the expression of antioxidant enzymes, namely catalase (CAD) and superoxide dismutase (SOD) $(17,18)$. Furthermore, atorvastatin exerts an anti-excitotoxic effect not depending on HMG-CoA reductase inhibition. The aforementioned impact is related to the decrease of NMDA receptor activity in neurons (16). The antidepressant-like effects of atorvastatin are suggested to be mediated by the blockade of the NMDA receptor (19).

\section{Objectives}

Considering the important etiological roles of oxidative stress, inflammation, and NMDA receptor overstimulation in the development of diabetic neuropathy and anti-oxidant anti-inflammatory properties and NMDA receptor modulatory effect of atorvastatin, the present study hypothesized the possibility of atorvastatin as a promising agent to ameliorate diabetic neuropathy. With this background in mind, the current study was carried out to evaluate the effectiveness of atorvastatin against streptozotocin (STZ)-induced changes in rat nerves following the development of diabetes.

\section{Methods}

\subsection{Animals}

A temperature of $22 \pm 2^{\circ} \mathrm{C}$, humidity of $80 \%, 12$ - hour light/dark cycle, and ad libitum access to food and water were the conditions in which male Wistar rats (weight range: 210-250 g) were kept. All the experimental procedures in this study were carried out in compliance with the regulations concerning the care and use of laboratory animals in Iran University of Medical Sciences, Tehran, Iran, (IR.IUMS.REC.1396.31971) and Principles of Laboratory Animal Care (National Institute of Health publication, revised in 1985).

\subsection{Chemicals}

Atorvastatin was provided by Sigma-Aldrich (St. Louis, MO, USA), and STZ was supplied by ZellBio (Germany). The measurement of malondialdehyde (MDA) levels and SOD activity was carried out using Teb Pazhouhan Razi assay kits (Tehran, Iran). Interleukin 1 beta (IL-1 $\beta$ ), interleukin 6 (IL-6), and tumor necrosis factor alpha (TNF- $\alpha$ ) kits were purchased from DuoSet ELISA (USA).

\subsection{Induction of diabetes mellitus}

The rats received an intraperitoneal injection of STZ $(65 \mathrm{mg} / \mathrm{kg})$ following overnight fasting. After a week, the blood glucose was measured using a glucometer (GlucoStar, USA) through a blood drop obtained from the tail vein. The rats with a blood glucose level of higher than $300 \mathrm{mg} / \mathrm{dL}$ were included in the experiment.

\subsection{Experimental plan}

A total of 40 rats were randomly assigned into six groups $(n=5-7)$, including the saline- and atorvastatin-treated controls, SZT-induced diabetic rats treated with vehicle, diabetic animals treated with morphine $(5 \mathrm{mg} / \mathrm{kg})$, and rats treated with atorvastatin $(10 \mathrm{mg} / \mathrm{kg} /$ day for 10 weeks $)$ alone or in combination with NMDA receptor agonist. Atorvastatin was orally given; however, morphine and NMDA were intraperitoneally injected at a single dose. The hot plate and formalin tests were carried out $30 \mathrm{~min}$ after the injection. At the end of the behavioral experiments, the control animals and diabetic rats treated with vehicle or atorvastatin were sacrificed, and dorsal root ganglia (DRG) were removed for molecular tests $(n=4)$.

\subsection{Hot plate test}

The rats were retained on a hot plate with a stable temperature of $55 \pm 1^{\circ} \mathrm{C}$. The latency time up to the presentation of the first signs of discomfort (i.e., hind paw lifting, hind paw licking, or jumping) in animals was recorded 30 min after the injections.

\subsection{Formalin test}

Formalin $(2.5 \%, 200 \mu \mathrm{l})$ was subcutaneously administered into the plantar surface of the right hind paw of the rats; subsequently, the duration of the licking and biting of the injected paw was 
recorded in 0-5 (i.e., the early phase) and 15-45 (i.e., the late phase) min after the formalin injection as a pain index.

\subsection{Real-time reverse transcription-polymerase chain reaction}

Real-time reverse transcription-polymerase chain reaction (RT-PCR) was applied for the investigation of the expression of GluN1, Glun2B, and $\beta$-actin in DRG. The isolation of DRG was carried out, and then liquid nitrogen was used in order to instantly immerse DRG. Total ribonucleic acid (RNA) was extracted from tissue homogenate using RNeasy Mini Kit (Qiagen, Germany). Subsequently, the first strand of complementary deoxyribonucleic acid (cDNA) was made through the utilization of $1 \mu \mathrm{g}$ of deoxyribonuclease treated RNA, $1 \mu$ l of random hexamer primer $(p(d N) 6)$, and ribonuclease free water, which were heated at $701 \mathrm{C}^{-}$for $5 \mathrm{~min}$; afterward, it was put on ice. RNasin as a ribonuclease inhibitor, 100 units of Moloney murine leukemia virus (M-MLV) reverse transcriptase, M-MLV buffer, and $0.4 \mathrm{mM}$ of deoxynucleoside triphosphates were added, and the combination was incubated at $421 \mathrm{C}$ for $1 \mathrm{~h}$. The oligonucleotide primers which were utilized in order to amplify polymerase chain reaction (PCR) were as follows:

Rat GluN1 forward: 5'-

CGGCTCTCTTGGAAGATACAGC- ${ }^{\prime}$, reverse: $5^{\prime}$ GTGGGAGTGAAGTGGTCGTT-3'

Rat GluN2B forward: 5'GTGAGAGCTCCTTTGCCAAC- $3^{\prime}$, reverse: $5^{\prime}$ TGAAGCAAGCACTGGTCATC-3'

Rat $\beta$-actin forward: $5^{\prime}$ TCATGAAGTGTGACGTTGACATCCGT-3', reverse: $5^{\prime}$ CCTAGAAGCATTTGCGGTGCAGGATG - $3^{\prime}$

Real-time PCR reaction consisted of $2 \mu \mathrm{l}$ of cDNA template, 10 pmol of each of forward and reverse primers, $6 \mu \mathrm{l}$ of distilled water, and $10 \mu \mathrm{l}$ of optimized PCR master mix (CinnaGen, Iran) in a total reaction volume of $20 \mu \mathrm{l}$ carried out using a Rotor-Gene machine (Qiagen, Germany). $\beta$-actin ribosomal ribonucleic acid was employed as an internal control gene in order to normalize the data of real-time PCR. The protocol of thermal cycling included the primary denaturation stage $\left(2 \mathrm{~min}\right.$ at $\left.94^{\circ} \mathrm{C}\right)$, followed by denaturation stage ( $2 \mathrm{~min}$ at $\left.94^{\circ} \mathrm{C}\right)$, annealing stage (30 sec at $60^{\circ} \mathrm{C}$ ), elongation stage (30 sec at $72^{\circ} \mathrm{C}$ ), and final extension ( $7 \mathrm{~min}$ at $\left.72^{\circ} \mathrm{O}\right)$. The levels of transcriptional differences between the groups were computed in proportion to the level of the expression of $\beta$-actin messenger ribonucleic acid (mRNA).

\subsection{Measurement of inflammatory cytokines}

Specific enzyme-linked immunosorbent assay kits were utilized in order to calculate the levels of IL-1 $\beta$, IL-6, and TNF- $\alpha$ in DRG. In short, each sample was homogenized in $1 \mathrm{ml}$ of phosphate-buffered saline
(PBS; pH 7.4); afterward, each sample was centrifuged at $10,000 \mathrm{~g}$ for $15 \mathrm{~min}$ at a temperature of $4^{\circ} \mathrm{C}$. Subsequently, the sample supernatant and kit reagents were added to the plate wells, and the measurement of the IL-1 $\beta$, IL- 6 , and TNF- $\alpha$ levels was carried out. A plate reader (Synergy HT, Biotek, USA) was applied in order to read absorbance at $450 \mathrm{~nm}$, and the levels of IL-1 $\beta$, IL- 6 , and TNF- $\alpha$ were computed and reported in $\mathrm{ng} / \mathrm{ml}$.

\subsection{Measurement of oxidative stress factors}

The SOD activity kit (Teb Pazhouhan Razi, Iran) was utilized in this study. In short, each DRG sample homogenate in PBS (pH 7.4) was centrifuged at 1,500 $\mathrm{g}$ for $5 \mathrm{~min}$ at a temperature of $4^{\circ} \mathrm{C}$. Afterward, the sample supernatant and kit reagents were added to plate wells and SOD activity was calculated. A plate reader (Synergy HT, Biotek, USA) was employed in order to read absorbance at a wavelength of $450 \mathrm{~nm}$, and SOD activity was measured and reported in unit/mg protein.

For the detection of the activity of CAT in DRG homogenates, a Catalase Assay Kit (Teb Pazhouhan Razi, Tehran, Iran) was employed in this study. Following the centrifugation of DRG homogenates at $10,000 \mathrm{~g}$ for $15 \mathrm{~min}$ at a temperature of $4^{\circ} \mathrm{C}$, supernatants $(20 \mu \mathrm{l})$ were mixed with assay buffer $(100 \mu \mathrm{l})$ and methanol $(30 \mu \mathrm{l})$ in the plate wells. Adding $\mathrm{H}_{2} \mathrm{O}_{2}(20 \mu \mathrm{l})$ to each well was the first step to start the reaction. Moreover, the plate was covered, incubated at room temperature, and shaken for 20 min. Adding stopper reagent $(30 \mu \mathrm{l})$ to each well was the final step to terminate the reaction. The chromogenic reagent $(30 \mu \mathrm{l})$ was added to each well and the plate was then covered, incubated at room temperature, and shaken for $10 \mathrm{~min}$. The plates were covered and shaken for $5 \mathrm{~min}$ at room temperature after the addition of the oxidizer reagent to each well. Formaldehyde standard was utilized as a standard reagent and CAT activity was determined and presented in units of enzyme per mg of protein.

The measurement of thiobarbituric acid reactive substances (as MDA equivalents, markers of lipid peroxidation) in DRG homogenate, including $150 \mathrm{mM}$ of potassium chloride, was carried out. A plate reader (Synergy HT, Biotek, USA) was utilized in order to read absorbance at a wavelength of $535 \mathrm{~nm}$, and the levels of MDA were measured and reported in $\mathrm{nmol} / \mathrm{mg}$ protein.

\subsection{Statistical analysis}

GraphPad Prism software (version 5) was employed in order to statistically analyze the data. The findings are presented as mean \pm standard error of the mean. One-way analysis of variance and then Tukey's post hoc test were utilized for the comparisons between the groups. A p-value of $\leq 0.05$ was considered statistically significant. 


\section{Results}

\subsection{Hot plate test}

The induction of diabetes resulted in a significant increase in the reaction time in comparison to that reported for the control group $(\mathrm{P} \leq 0.01)$. The pretreatment of diabetic rats using atorvastatin demonstrated analgesic effects in comparison to the treatment of the diabetic animals with vehicle $(\mathrm{P} \leq 0.01)$; however, the injection of NMDA could significantly reverse the results $(\mathrm{P} \leq 0.05)$. In addition, the use of morphine resulted in the production of analgesic properties in comparison to those reported for the diabetic vehicle-treated group ( $\mathrm{P} \leq 0.001$; Figure 1A).

\subsection{Formalin test}

In the early phase, STZ-induced diabetic rats revealed a significant reduction in licking and biting time in comparison to that reported for the control group $(\mathrm{P} \leq 0.05)$. Furthermore, the pretreatment of diabetic rats using atorvastatin indicated analgesic characteristics in comparison to the treatment of diabetic animals with vehicle $(\mathrm{P} \leq 0.05)$. The injection of NMDA exerted hyperalgesia in the groups of

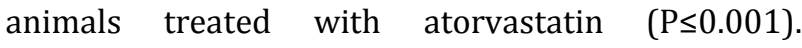
Additionally, the use of morphine also demonstrated analgesic characteristics in comparison to the treatment of the diabetic rats with vehicle $(\mathrm{P} \leq 0.05$; Figure 1B).

In the late phase, the diabetic group showed analgesia, compared to the control group $(\mathrm{P} \leq 0.0001)$, and atorvastatin did not alter that $(P>0.05)$. The injection of NMDA could not change the licking and biting time in the groups treated with atorvastatin $(\mathrm{P}>0.05)$. The use of morphine showed significant analgesic characteristics in comparison to the treatment of the diabetic rats with vehicle $(\mathrm{P} \leq 0.0001$; Figure 1C).

\subsection{Real-time reverse transcription-polymerase chain reaction}

The obtained data from quantitative RT-PCR showed that although diabetes elevated the expression of GluN2B and GluN1 mRNA in rat DRG and the use of atorvastatin might decrease it, there was no statistical significance with regard to the differences ( $P>0.05$; Figure 2).
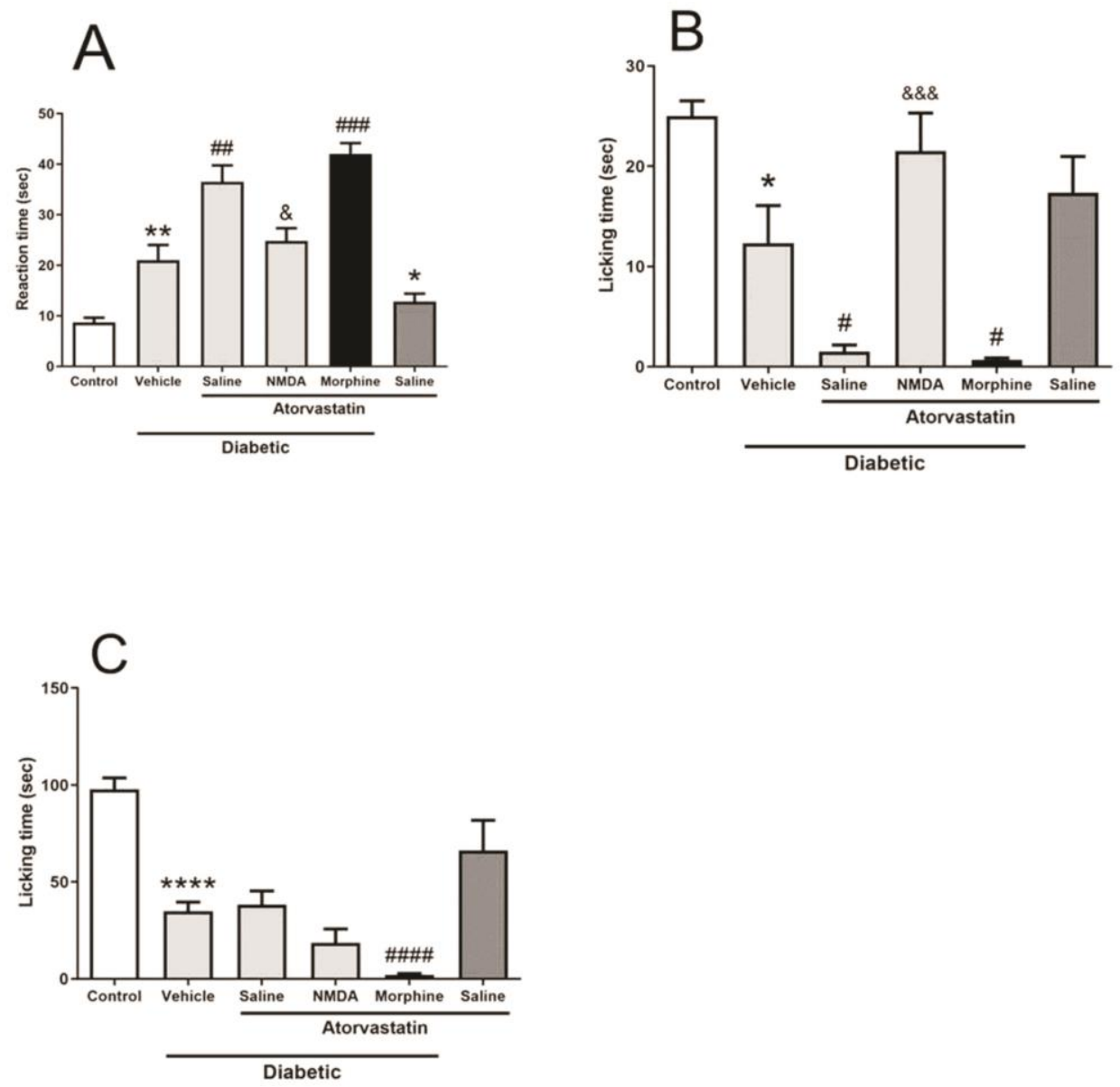

Figure 1. Nociceptive behavior in hot plate test (A) and early (B) and late (C) phases of formalin test in different groups; results presented as mean \pm standard error of the mean ( $\mathrm{n}=5-7)$; ${ }^{*} \mathrm{P} \leq 0.05,{ }^{* *} \mathrm{P} \leq 0.01$, and ${ }^{* * *} \mathrm{P} \leq 0.0001$ compared to those of control group;

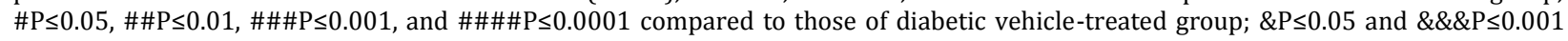
compared to those of diabetic saline-injected atorvastatin-treated group 
A

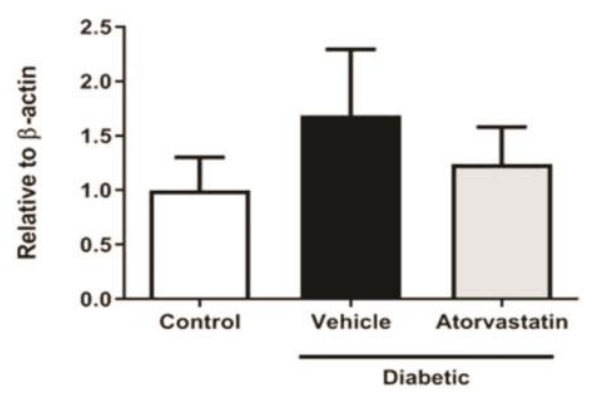

B

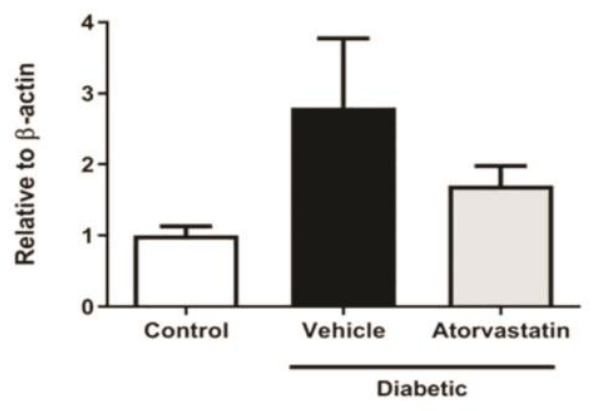

Figure 2. Expressions of GluN1 (A) and GluN2B (B) messenger ribonucleic acid (mRNA) in different groups; $\beta$-actin mRNA served as a housekeeping gene; results presented as mean \pm standard error of the mean $(n=4)$

\subsection{Measurement of inflammatory cytokines}

Diabetes resulted in the elevation of the levels of IL-1 $\beta$, IL-6, and TNF- $\alpha$ in DRG in comparison to those reported for the control group $(\mathrm{P} \leq 0.05)$, and the pretreatment of the diabetic animals using atorvastatin could significantly reverse the increase in the levels of TNF- $\alpha(\mathrm{P} \leq 0.05$; Figure 3$)$.

\subsection{Measurement of oxidative stress factors}

There was no significant difference in MDA levels and SOD and CAT activities among the studied groups $(\mathrm{P}>0.05$; Figure 4$)$.
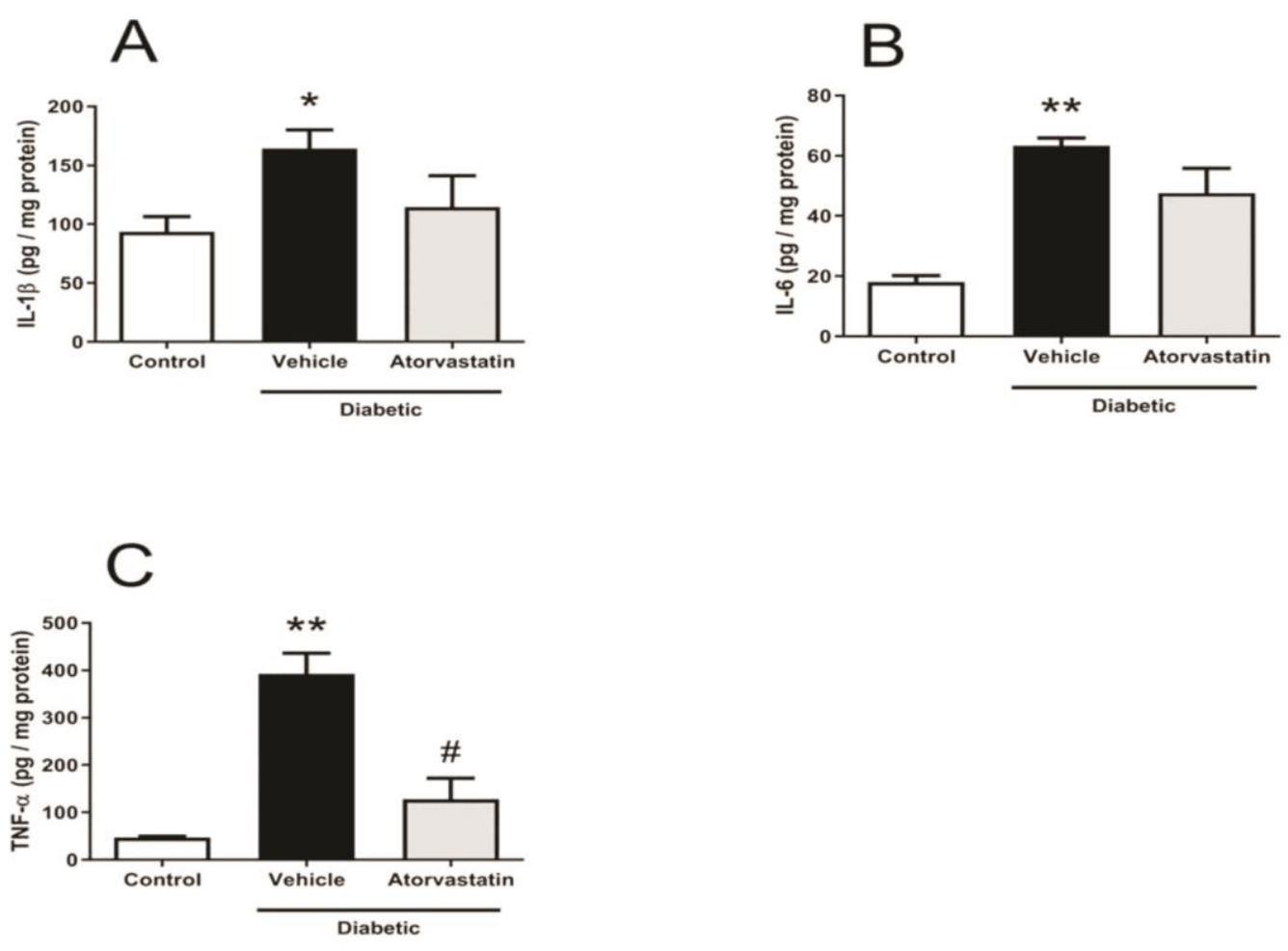

Figure 3. Levels of interleukin 1 beta (A), interleukin 6 (B), and tumor necrosis factor alpha (C) in different groups; results presented as mean \pm standard error of the mean $(\mathrm{n}=4){ }^{*} \mathrm{P} \leq 0.05$ and ${ }^{*} \mathrm{P} \leq 0.01$ compared to those of control group; \#P $\leq 0.05$ compared to those of diabetic vehicle-treated group

\section{Discussion}

Diabetes has several complications among which diabetic neuropathy is regarded as a common chronic complication which is identified by severe pain, cachexia, weight loss, and depression in diabetic patients (5). Since diabetes mellitus is associated with lipid abnormalities and cardiovascular events in diabetics, it is necessary to receive cholesterollowering treatment in order to decrease the risk of 

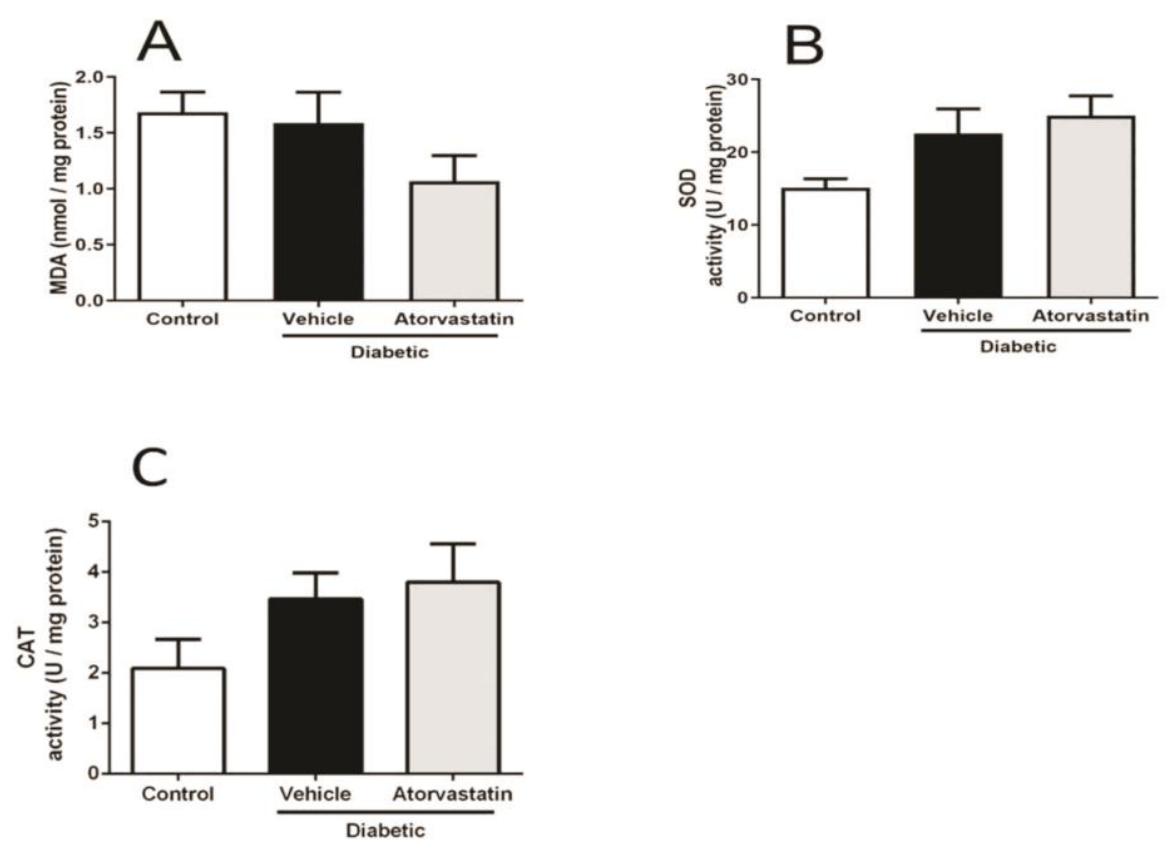

Figure 4. Malondialdehyde level (A) and superoxide dismutase (B) and catalase (C) activities in different groups; results presented as mean \pm standard error of the mean $(n=4)$

cardiovascular events. The first-line lipid-lowering treatment of diabetics is considered statins despite clinical trials and meta-analyses indicating that longterm statin treatment increases the risk of the development of new-onset type 2 diabetes mellitus (20). Due to the fact that statins, such as atorvastatin, have several effects on the modification of dyslipidemia related to diabetes, the current study was carried out to investigate the in vivo effects of atorvastatin on the complications of diabetes, namely neuropathy.

Oxidative stress, as a result of a high-glucose condition in peripheral nerves, is the main causative factor incriminated in the development of diabetic neuropathy (21). The rate of advanced glycation end product (AGE) formation increases during hyperglycemia due to the attachment of reactive carbohydrate groups to proteins, nucleic acids, or lipids. The aforementioned AGEs have harmful potential and directly affect cellular function. Furthermore, the binding of AGEs to the receptor of AGE starts a downstream intracellular cascade resulting in the activation of NADPH oxidases, generation of ROS, and induction of inflammatory responses (22).

In addition, extra glucose decreases to sorbitol by aldose reductase, which is subsequently oxidized to fructose through sorbitol dehydrogenase. This pathway, known as the polyol pathway, is associated with the consumption of NADPH. Since efficient regeneration reduced glutathione (GSH) requires a sufficient supply of NADPH, the depletion of NADPH directly contributes to oxidative stress (22). Reactive radicals lead to the impairment of mitochondrial function and activation of various signaling pathways, such as mitogen-activated protein kinases and nuclear factor kappa B (NF- $\mathrm{B}$ ). The aforementioned results of the upregulation of inflammatory cytokines and apoptotic protein expressions contribute to neuronal damage and finally death (21).

The obtained results of the current study indicated that diabetes causes an increase in neuronal oxidative stress and expression of inflammatory cytokines. The levels of MDA (as an index of lipid peroxidation), IL-1 $\beta$, IL- 6 , and TNF- $\alpha$ increased; nevertheless, the activities of CAT and SOD antioxidant enzymes decreased in diabetic rats. Although the antioxidant activity of atorvastatin has been demonstrated by previous in vitro and in vivo investigations, the treatment with atorvastatin could not reverse the oxidative stress in diabetic animals.

In the present study, only the MDA level and SOD and CAT activities were measured. The data obtained from previous studies suggest that atorvastatin may exert antioxidant activity through various mechanisms. Atorvastatin has been shown to be mediated via the activation of the nuclear factor erythroid 2-related factor 2/antioxidant response element signaling pathway resulting in the elevation of the expression and activity of detoxifying and antioxidant enzymes, namely heme oxygenase- 1 , $\mathrm{NAD}(\mathrm{P}) \mathrm{H}$ quinone oxidoreductase, glutathione $\mathrm{S}$ transferase, SOD, and glutathione peroxidase (23). In chronic construction injury-induced neuropathic rats, the use of atorvastatin improves the activity of antioxidant enzymes, such as CAT and GST, and the levels of GSH and total thiol, resulting in the reduction of the generation of MDA, ROS, and nitrite 
oxide (24). Atorvastatin prevents the disturbances of mitochondria membrane potential leading to the improvement of mitochondrial energetic metabolism and reduction of oxidative stress; this effect is important in neurodegenerative disorders induced by mitochondrial deficits (25).

The excessive level of oxidized low-density lipoproteins leads to the ROS-mediated activation of NF- $\mathrm{KB}$ in the endothelial cells of the peripheral nervous system (26). Furthermore, NMDA induces a $\mathrm{Ca}^{2+}$-dependent activation of NF- $\mathrm{kB}$, which subsequently results in the activation of inflammatory cascades (27). Statins, such as atorvastatin, inhibit the activation of NF- $\mathrm{KB}$ and activator protein-1 signaling pathways causing the suppression of the expression of inflammatory cytokines, namely IL-1 $\beta$, interleukin 2 , IL-6, interleukin 12 , and TNF- $\alpha(28,29)$. The findings of the present study also revealed that the use of atorvastatin suppressed the generation of TNF- $\alpha$ in diabetic animals with neuropathy, which is in line with the aforementioned results.

The obtained findings of the behavioral tests demonstrated that diabetes caused analgesia in diabetic rats. Atorvastatin not only could not reverse the diabetes-induced analgesia but also exerted analgesic effects in the hot plate and formalin tests. The administration of NMDA reversed the analgesic effect of atorvastatin suggesting that atorvastatininduced analgesia might be mediated through the inhibition of the NMDA receptor.

Although the findings of the present study indicated that atorvastatin did not influence the expression of the NMDA receptor in DRG, this analgesic effect may result from the inhibition of NMDA receptor activity. Atorvastatin has been reported to protect cortical neurons from excitotoxic cell death through the modulation of NMDA receptor function. In addition, atorvastatin reduces NMDAreceptor-mediated intracellular calcium increase. Since mevalonate or isoprenoid co-treatment could not reverse the anti-excitotoxic effects of atorvastatin, this effect is proposed to be independent of the inhibition of HMG-CoA reductase (16).

\section{Conclusion}

According to the obtained results of the present study, it was revealed that the inflammatory process has a significant role in the development of diabetic neuropathy. Atorvastatin exacerbates the analgesic effects of diabetes, which could be at least in part through the modulation of the inflammatory cytokines and probably NMDA receptor activity, not expression.

\section{Footnotes}

Authors' Contribution: Conception and design: VN and AH; performing the experiments: MYK, NN, and MRA; analyzing the data: MA; drafting the manuscript: all the authors; approving the final version: all the authors; responsibility for the integrity of the work as a whole: VN.

Conflict of Interests: The authors declare that there is no conflict of interest.

Ethical Approval: All the experimental procedures were carried out in accordance with the guidelines for the care and use of laboratory animals at Iran University of Medical Sciences (IR.IUMS.REC.1396. 31971).

Funding/Support: This study was funded by the Deputy of Research of Iran University of Medical Sciences, Tehran, Iran (grant number: 96-03-11831971).

Informed consent: Not applicable.

\section{References}

1. Cheung N, Mitchell P, Wong TY. Diabetic retinopathy. Lancet. 2010;376(9735):124-36. doi: 10.1016/S0140-6736(09)621243. [PubMed: 20580421].

2. Hosseinzadeh A, Juybari KB, Kamarul T, Sharifi AM. Protective effects of atorvastatin on high glucose-induced oxidative stress and mitochondrial apoptotic signaling pathways in cultured chondrocytes. J Physiol Biochem. 2019;75(2):153-62. doi: 10.1007/s13105-019-00666-8. [PubMed: 30796627].

3. Caporale JE, Elgart JF, Gagliardino JJ. Diabetes in Argentina: cost and management of diabetes and its complications and challenges for health policy. Global Health. 2013;9(54). doi: 10.1186/1744-8603-9-54. [PubMed: 24168330].

4. Agarwal AS, Fuladi AB, Mishra G, Tayade BO. Spirometry and diffusion studies in patients with type-2 diabetes mellitus and their association with microvascular complications. Indian J Chest Dis Allied Sci. 2010;52(4):213-6. [PubMed: 21302598].

5. Bansal V, Kalita J, Misra UK. Diabetic neuropathy. Postgrad Med J. 2006;82(964):95-100. doi: 10.1136/pgmj.2005.036137. [PubMed: 16461471].

6. Vinik AI, Strotmeyer ES, Nakave AA, Patel CV. Diabetic neuropathy in older adults. Clin Geriatr Med. 2008;24(3):407 35,v. doi: 10.1016/j.cger.2008.03.011. [PubMed: 18672180].

7. Yagihashi S, Yamagishi SI, Wada R. Pathology and pathogenetic mechanisms of diabetic neuropathy: correlation with clinical signs and symptoms. Diabetes Res Clin Pract. 2007;77Suppl 1:S184-9. doi: 10.1016/j.diabres.2007.01.054. [PubMed: 17462777]

8. Lai AK, Lo AC. Animal models of diabetic retinopathy: summary and comparison. J Diabetes Res. 2013;2013:106594. doi: 10.1155/2013/106594. [PubMed: 24286086].

9. El-Asrar AM. Role of inflammation in the pathogenesis of diabetic retinopathy. Middle East Afr J Ophthalmol. 2012;19(1):70-4. doi: 10.4103/0974-9233.92118. [PubMed: 22346117].

10. Zhu S, Stein RA, Yoshioka C, Lee CH, Goehring A, Mchaourab HS, et al. Mechanism of NMDA receptor inhibition and activation. Cell. 2016;165(3):704-14. doi: 10.1016/j.cell.2016.03.028. [PubMed: 27062927].

11. Zhou HY, Chen SR, Pan HL. Targeting N-methyl-D-aspartate receptors for treatment of neuropathic pain. Expert Rev Clin Pharmacol. 2011;4(3):379-88. doi: 10.1586/ecp.11.17. [PubMed: 21686074].

12. Collins S, Sigtermans MJ, Dahan A, Zuurmond WWA, Perez RSGM. NMDA receptor antagonists for the treatment of neuropathic pain. Pain Med. 2010;11(11):1726-42. doi: 10.1111/j.1526-4637.2010.00981.x. [PubMed: 21044263].

13. Aiyer R, Mehta N, Gungor S, Gulati A. A systematic review of nmda receptor antagonists for treatment of neuropathic pain in clinical practice. Clin J Pain. 2018;34(5):450-67. doi: 10.1097/AJP.0000000000000547. [PubMed: 28877137].

14. Chen SR, Samoriski G, Pan HL. Antinociceptive effects of chronic 
administration of uncompetitive NMDA receptor antagonists in a rat model of diabetic neuropathic pain. Neuropharmacology. 2009;57(2):121-6. doi: 10.1016/j.neuropharm.2009.04.010. [PubMed: 19422840].

15. Wu QJ, Tymianski M. Targeting NMDA receptors in stroke: new hope in neuroprotection. Mol Brain. 2018;11(1):15. doi: 10.1186/s13041-018-0357-8. [PubMed: 29534733].

16. Bösel J, Gandor F, Harms C, Synowitz M, Harms U, Djoufack PC, et al. Neuroprotective effects of atorvastatin against glutamate-induced excitotoxicity in primary cortical neurones. J Neurochem. 2005;92(6):1386-98. doi: 10.1111/j.14714159.2004.02980.x. [PubMed: 15748157].

17. Ghaisas MM, Dandawate PR, Zawar SA, Ahire YS, Gandhi SP. Antioxidant, antinociceptive and anti-inflammatory activities of atorvastatin and rosuvastatin in various experimental models. Inflammopharmacology. 2010;18(4):169-77. doi: 10.1007/s10787-010-0044-6. [PubMed: 20532641].

18. Rayegan S, Dehpour AR, Sharifi AM. Studying neuroprotective effect of Atorvastatin as a small molecule drug on high glucoseinduced neurotoxicity in undifferentiated PC12 cells: role of NADPH oxidase. Metab Brain Dis. 2017;32(1):41-9. doi: 10.1007/s11011-016-9883-1. [PubMed: 27476541].

19. Ludka FK, Constantino LC, Dal-Cim T, Binder LB, Zomkowski A, Rodrigues ALS, et al. Involvement of PI3K/Akt/GSK-3 $\beta$ and mTOR in the antidepressant-like effect of atorvastatin in mice. J Psychiatr Res. 2016;82:50-7. doi: 10.1016/ j.jpsychires.2016.07.004. [PubMed: 27468164].

20. Sattar NA, Ginsberg H, Ray K, Chapman MJ, Arca M, Averna M, et al. The use of statins in people at risk of developing diabetes mellitus: evidence and guidance for clinical practice. Atherosclerosis Suppl. 2014;15(1):1-15. doi: 10.1016/j. atherosclerosissup.2014.04.001. [PubMed: 24840509].

21. Park Y. Chapter 1 - Oxidative Stress and Diabetic Neuropathy. In: Preedy VR, editor. Diabetes: Oxidative Stress and Dietary Antioxidants. San Diego: Academic Press; 2014. p. 3-13.

22. Hosseini A, Abdollahi M. Diabetic neuropathy and oxidative stress: therapeutic perspectives. Oxid Med Cell Longev.
2013;2013:168039. doi: 10.1155/2013/168039. [PubMed: 23738033].

23. Sun G, Li Y, Ji Z. Atorvastatin attenuates inflammation and oxidative stress induced by ischemia/reperfusion in rat heart via the Nrf2 transcription factor. Int J Clin Exp Med. 2015;8(9):14837-45. [PubMed: 26628965].

24. Pathak NN, Balaganur V, Lingaraju MC, Kant V, Latief N, More AS, et al. Atorvastatin attenuates neuropathic pain in rat neuropathy model by down-regulating oxidative damage at peripheral, spinal and supraspinal levels. Neurochem Int. 2014;68:1-9. doi: 10.1016/j.neuint.2014.01.014. [PubMed: 24513038].

25. Massari CM, Castro AA, Dal-Cim T, Lanznaster D, Tasca CI. In vitro 6-hydroxydopamine-induced toxicity in striatal, cerebrocortical and hippocampal slices is attenuated by atorvastatin and MK-801. Toxicol Vitro. 2016;37:162-8. doi: 10.1016/j.tiv.2016.09.015. [PubMed: 27647473].

26. Pergolizzi JV, Magnusson P, LeQuang JA, Razmi R, Zampogna G, Taylor R. Statins and neuropathic pain: a narrative review. Pain Ther. 2020;9(1):97-111. doi: 10.1007/s40122-02000153-9. [PubMed: 32020545].

27. Snow WM, Albensi BC. Neuronal gene targets of NF- $\kappa \mathrm{B}$ and their dysregulation in Alzheimer's disease. Front Mol Neurosci. 2016;9:118. doi: 10.3389/fnmol.2016.00118. [PubMed: 27881951].

28. Barsante MM, Roffê E, Yokoro CM, Tafuri WL, Souza DG, Pinho $\mathrm{V}$, et al. Anti-inflammatory and analgesic effects of atorvastatin in a rat model of adjuvant-induced arthritis. Eur J Pharmacol. 2005;516(3):282-9. doi: 10.1016/j.ejphar.2005.05.005. [PubMed: 15970284].

29. Dichtl W, Dulak J, Frick M, Alber HF, Schwarzacher SP, Ares MP, et al. HMG-CoA reductase inhibitors regulate inflammatory transcription factors in human endothelial and vascular smooth muscle cells. Arterioscler Thromb Vasc Biol. 2003; 23(1):58-63. doi: 10.1161/01.atv.0000043456.48735.20. [PubMed: 12524225]. 